\title{
Modelos experimentais de deficiência limbar em coelhos - análise clínica
}

\author{
Experimental models oflimbal stem cell deficiency in rabbits - clinical study
}

\author{
Daniel Ramos Parente ${ }^{1}$ \\ Maria Rosa Bet de Moraes Silva ${ }^{2}$ \\ Raimundo Gerônimo da Silva Júnior ${ }^{3}$ \\ Mariângela de Alencar Marques ${ }^{4}$
}

\footnotetext{
Mestre em cirurgia, área de concentração Bases Gerais da Cirurgia e Cirurgia Experimental, da Faculdade de Medicina de Botucatu - Universidade Estadual de São Paulo.

${ }^{2}$ Professora Assistente Doutora do Departamento de Oftalmologia, Otorrinolaringologia e Cirurgia de Cabeça e Pescoço da Faculdade de Medicina de Botucatu Universidade Estadual de São Paulo.

${ }^{3}$ Ex-residente do Departamento de Anatomia Patológica da Faculdade de Medicina de Botucatu - Universidade Estadual de São Paulo.

${ }^{4}$ Professora Doutora do Departamento de Anatomia Patológica da Faculdade de Medicina de Botucatu - Universidade Estadual de São Paulo.

Endereço para correspondência: Dep. Oftalmologia/ Otorrinolaringologia/Cirurgia de Cabeça e Pescoço Faculdade de Medicina de Botucatu - UNESP - Botucatu (SP) CEP 18618-000.

E-mail: rosabet@fmb.unesp.br

Nota Editorial: Pela análise deste trabalho e por sua anuência sobre a divulgação desta nota, agradecemos ao Dr. José Álvaro Pereira Gomes.

Recebido para publicação em 17.01.2001

Aceito para publicação em 17.07.2001
}

\section{RESUMO}

Objetivo: Comparar em coelhos três modelos experimentais de destruição das células germinativas (CG) do limbo corneano quanto a aspectos clínicos. Métodos: Foram utilizados 54 coelhos, 108 olhos, subdivididos em 3 grupos experimentais: (G1), (G2)e (G3), cada um formado pelos OE de 18 coelhos, submetidos às técnicas experimentais (T1), (T2) e (T3), respectivamente, e um grupo controle, formado pelos 54 olhos contralaterais (OD). Nas três técnicas foi utilizado o n-heptanol. Na T1, o n-heptanol foi aplicado por 5 minutos, para remoção do epitélio límbico. Na T2, além da aplicação do n-heptanol, realizou-se peritomia e remoção da conjuntiva perilímbica até $4 \mathrm{~mm}$ do limbo, juntamente com a escarificação do tecido episcleral. $\mathrm{Na}$ T3, além dos procedimentos da T2, foi realizada dissecção lamelar do limbo abrangendo aproximadamente $1,5 \mathrm{~mm}$ na periferia da córnea e $2 \mathrm{~mm}$ na superfície escleral. Em todas as córneas dos animais foram estudados seis parâmetros clínicos: neovascularização, perda da transparência, irregularidade da superfície, reparação epitelial, erosão ou defeito epitelial, granuloma e outras lesões corneanas. Resultados: A neovascularização corneana iniciou-se mais precocemente com a T1 e T2; ocorreu em $100 \%$ dos casos com as três técnicas, de forma não homogênea, variando de leve a intensa; permaneceu estável a partir do $28^{\circ}$ dia até o final do experimento ( $56^{\circ}$ dia), foi maior nos quadrantes superior e inferior e menor nos quadrantes nasal e temporal. A perda da transparência e a irregularidade da superfície corneana foram menores com a T1 que com a T2 e T3, que foram similares entre si. Houve, nas três técnicas experimentais, latência de três dias para o início da reepitelização, que se completou com a T1 no 7음 dia e com a T2 e T3 no 14ํ dia. Erosão epitelial corneana e granuloma corneano foram encontradas de forma similar nas três técnicas experimentais. Conclusões: A T2 e T3 mostraram-se adequadas como possíveis modelos de ampla remoção das CG límbicas, levando a resultados similares nos diversos parâmetros estudados. A T1 se mostrou adequada como modelo de remoção parcial do epitélio límbico. Ocorreu conjuntivalização e neovascularização nas três técnicas experimentais.

Descritores: Células germinativas; Limbo da córnea; Modelos animais; Coelhos

\section{INTRODUCÃ̃O}

A superfície ocular normal é recoberta pelos epitélios conjuntival, límbico e corneano. Os três são epitélios estratificados e não queratinizados, porém compostos por células de fenótipos diferentes ${ }^{(1)}$. O epitélio límbico, assim como o epitélio corneano, não possui células caliciformes, porém, como o epitélio conjuntival, encontra-se sobreposto a um leito 
vascularizado, estando seu funcionamento intrinsecamente relacionado a influências vasculares ${ }^{(1)}$. O epitélio límbico é a sede da localização de células germinativas $(\mathrm{CG})$ responsáveis pela regeneração do epitélio corneano ${ }^{(1)}$. Estes epitélios interagem entre si e com o filme lacrimal e, em condições normais, mantêm-se em perfeito estado de equilíbrio, fundamental para a integridade da superfície ocular ${ }^{(2)}$. Essa interrelação, quando normal, proporciona uma visão clara, conforto ocular e serve como primeira linha de defesa contra agentes microbianos externos.

Vários modelos de disfunção das CG límbicas têm sido propostos para simular as alterações encontradas nas doenças da superfície ocular, de forma a servir como meio para melhor estudá-las ${ }^{(4-8)}$. Com uma superfície conjuntivalizada e neovascularizada, poderá ser avaliada a eficácia de uma proposta terapêutica em restabelecer uma superfície ocular próxima do normal, por meio da regressão dos neovasos, da recuperação do fenótipo epitelial corneano original e do retorno à transparência corneana.

No entanto, os modelos experimentais de deficiência limbar apresentam resultados variáveis em relação à reprodutibilidade, regularidade e grau de neovascularização corneana. Devido à necessidade de padronização nos estudos sobre fisiopatologia e terapêutica das desordens da superfície ocular, propõe-se, nesse trabalho, comparar clinicamente três modelos experimentais de deficiência limbar em coelhos (remoção dos epitélios corneano e límbico $(\mathrm{T} 1)^{(4-5)}$, remoção dos epitélios corneano e límbico e do tecido límbico sub-epitelial (T2) ${ }^{(6)}$ e remoção do epitélio corneano e dissecção lamelar do limbo (T3) ${ }^{(7-8)}$.

\section{MÉTODOS}

Foram utilizados 54 coelhos, da raça Norfolk 2.000 , fêmeas, pesando entre 1500 e $2200 \mathrm{~g}$, com idade variando de 4 a 6 meses. Os 108 olhos, subdivididos em 3 grupos experimentais: (G1), (G2) e (G3), cada um formado pelos OE de 18 coelhos, submetidos às técnicas experimentais (T1), (T2) e (T3), respectivamente, e um grupo controle, formado pelos 54 olhos contralaterais (OD). Foram observadas as recomendações para experiência em animais estabelecidas pela Comissão de Ética em Experimentação Animal do Campus de Botucatu - UNESP.

Os coelhos foram anestesiados para realização dos procedimentos com o anestésico pentobarbital sódico (Thionembutal ${ }^{\circledR}$, Abbot Laboratórios do Brasil Ltda., São Paulo) na dose de $30 \mathrm{mg} / \mathrm{kg}$, complementada com instilação tópica de uma gota de proximetacaína 0,5\% (Anestalcon ${ }^{\circledR}$, Alcon, São Paulo). A seguir são descritas as técnicas experimentais (Figura 1):

1. Técnica 1 (T1): remoção dos epitélios corneano e límbico

Com uma esponja de celulose, foi feita aplicação do n-heptanol (Merck-Schuchardt, Hohenbrunn, Munique) na totalidade da superfície corneana, no limbo e na conjuntiva perilimbar distante até $4 \mathrm{~mm}$ do limbo, durante 5 minutos. Em seguida, o excedente do n-heptanol foi removido com a lavagem do olho com $50 \mathrm{ml}$ de solução salina.

2. Técnica 2 (T2): remoção dos epitélios corneano e límbico e do tecido límbico sub-epitelial

A fase inicial deste segundo procedimento foi semelhante a T1. Após a remoção do excesso de n-heptanol, foi realizada peritomia em $360^{\circ}$, retirando-se a conjuntiva límbica e bulbar até $4 \mathrm{~mm}$ do limbo, com tesoura tipo Vannas. Após a peritomia, com remoção também do tecido sub-epitelial, foi feita escarificação do tecido episcleral na região do limbo, utilizando-se lâmina de bisturi no 15 .

3. Técnica 3 (T3): remoção do epitélio corneano e dissecção lamelar do limbo

Além dos procedimentos realizados para T2, procedeu-se a dissecção lamelar do limbo, em 360º, utilizando-se uma lâmi-

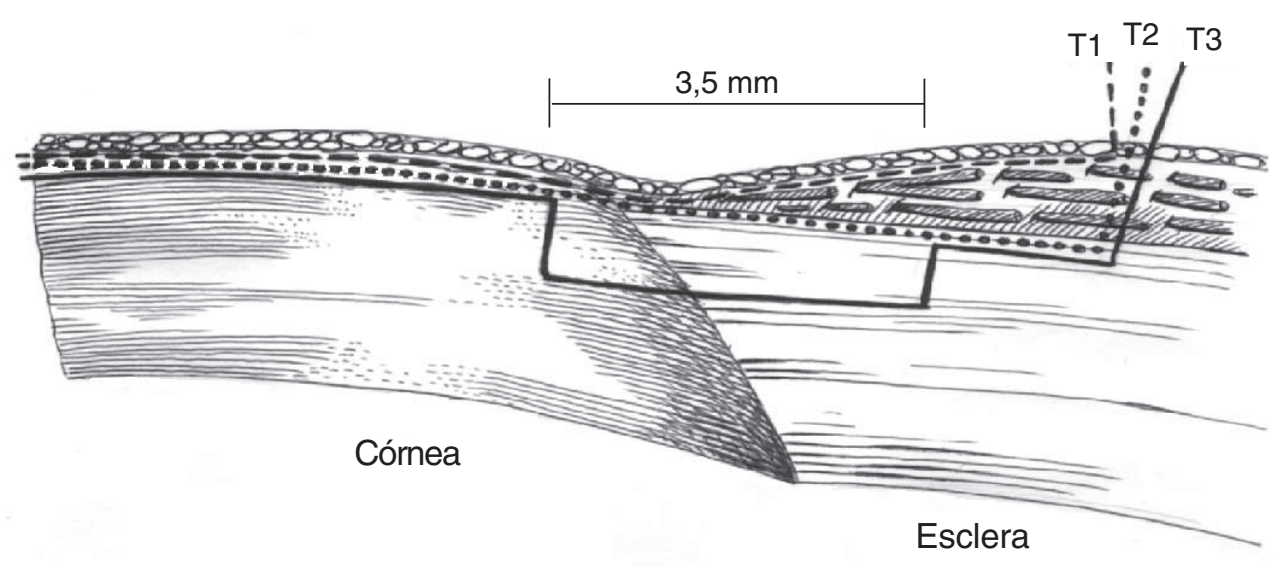

Figure 1 - Esquema representativo das três técnicas experimentais; linha tracejada (T1), linha pontilhada (T2), linha contínua (T3) 
na de bisturi B 6660 DK (Allergan Medical Optics, Inc., Irvine, CA, USA), abrangendo aproximadamente $1,5 \mathrm{~mm}$ da córnea perilímbica e $2 \mathrm{~mm}$ do limbo escleral.

Ao final dos três procedimentos, a desepitelização da córnea, do limbo e da conjuntiva adjacente foi completada passando-se cotonete seco sobre estas superfícies e comprovada pela aplicação de gotas de fluoresceína sódica na superfície desnuda.

Após realização dos procedimentos foi instilado colírio de gentamicina (Gentamicina ${ }^{\circledR}$, Allergan, São Paulo) 2 vezes ao dia até o completo fechamento da ferida cirúrgica.

Foram avaliados seis parâmetros clínicos das córneas dos animais: neovascularização, perda da transparência, irregularidade da superfície, reparação epitelial, erosão ou defeito epitelial e presença de granuloma.

1. Neovascularização: foi classificada, de acordo com a proliferação vascular sobre a córnea ${ }^{(9)}$, em 5 classes: 0 , ausente; $1(+)$, proliferação vascular até $2 \mathrm{~mm}$ do limbo; $2(+)$, de 2 a 4 $\mathrm{mm}$ do limbo; 3(+), de 4 a $6 \mathrm{~mm}$ do limbo; 4(+), atingindo o centro, nos quatro quadrantes corneanos: superior $(\mathrm{S})$, inferior $(\mathrm{I})$, temporal $(\mathrm{T})$ e nasal $(\mathrm{N})$. O somatório dos valores por quadrantes representou um valor de neovascularização "global". A córnea foi considerada vascularizada quando apresentou neovasos acima de $2 \mathrm{~mm}$ em pelo menos dois quadrantes. Para efeito de apresentação, os valores da neovascularização global foram enquadrados em três subdivisões: leve, correspondendo a valores até 6 ; moderada, para valores de neovascularização global entre 7 e 10; intensa, para valores de neovascularização acima de 10 .

2. Perda da transparência: foi classificada, de acordo com a dificuldade em se observarem detalhes da íris, em 5 classes: 0 , quando não houve dificuldade para observação de detalhes da íris; $1(+)$, quando houve um pouco de borramento dos detalhes da íris; $2(+)$, quando houve maior dificuldade em definir detalhes da íris; 3(+), quando não foi possível ver detalhes da íris; 4(+), quando não se observou a íris.

3. Irregularidade da superfície: a superfície corneana, após reepitelização, foi classificada em lisa, 0 , ou irregular de $1(+)$ a $3(+)$ : $1(+)$, irregularidade leve; $2(+)$, moderada; $3(+)$ intensa), de acordo com a presença de lesões tipo puntata após coloração com fluoresceína.

4. Reparação epitelial: para classificação, as fotografias dos olhos foram colocadas sob papel vegetal transparente milimetrado, sendo, a seguir, delimitadas, no papel, as margens da área total da córnea e da área sem epitélio. Após contagem dos quadrados no interior das áreas delimitadas, obtinham-se os valores em milímetros quadrados correspondente à fotografia. $\mathrm{O}$ valor da área sem epitélio foi, em seguida, transformado em percentual da área total da córnea.

5. Erosão ou defeito epitelial: foi anotada a presença $(\mathrm{P})$ ou ausência (A) de erosões epiteliais recorrentes ou defeitos epiteliais persistentes, que foram definidas como solução de continuidade epitelial contínua com diâmetro maior que $1 \mathrm{~mm}$.

6. Granuloma: foi anotada presença (P) ou ausência (A) de lesões tipo granuloma corneano.

Outras lesões corneanas: o surgimento de achados não esperados foram assinalados, sendo feita uma descrição pormenorizada dos detalhes.

Os parâmetros clínicos foram avaliados em 7 momentos

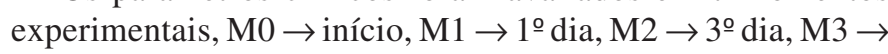
$7^{\circ}$ dia, M4 $\rightarrow 14^{\circ}$ dia, M5 $\rightarrow 28^{\circ}$ dia e M6 $\rightarrow 56^{\circ}$ dia ou até que o coelho fosse sacrificado.

Foi feita análise estatística dos resultados, utilizando-se a mediana para caracterizar a tendência central dos grupos e dois métodos de análise não paramétricos para as comparações entre os grupos experimentais: prova de Kruskal-Wallis e prova de Friedman. As diferenças foram consideradas significativas quando $p<0,05$. Nos casos em que $0,05<p<0,10$ foi referida tendência a diferença.

\section{RESULTADOS}

\section{Neovascularização}

A neovascularização da córnea iniciou-se entre 7 e 15 dias após a realização das técnicas experimentais, tendo sido mais precoce na T1 e T2 do que na T3 (Figura 2). Em M3 (7ㅇ dia) e M4 (14을 dia), ela se distribuiu na periferia da córnea em $360^{\circ}$, de forma igual entre os quadrantes. Houve, então, a progressão da neovascularização em direção ao centro da córnea até M5 (28ํ dia), mantendo-se estável no momento seguinte M6 (56º dia) (Gráfico 1, Figura 3). O aumento da neovascularização, ao longo dos momentos, foi estatisticamente significativo para os três grupos experimentais.

As três técnicas experimentais produziram algum grau de neovascularização em $100 \%$ dos casos. No M5 até o final do experimento (M6), a neovascularização variou de leve a intensa. É preciso lembrar que nenhuma das três técnicas produziu

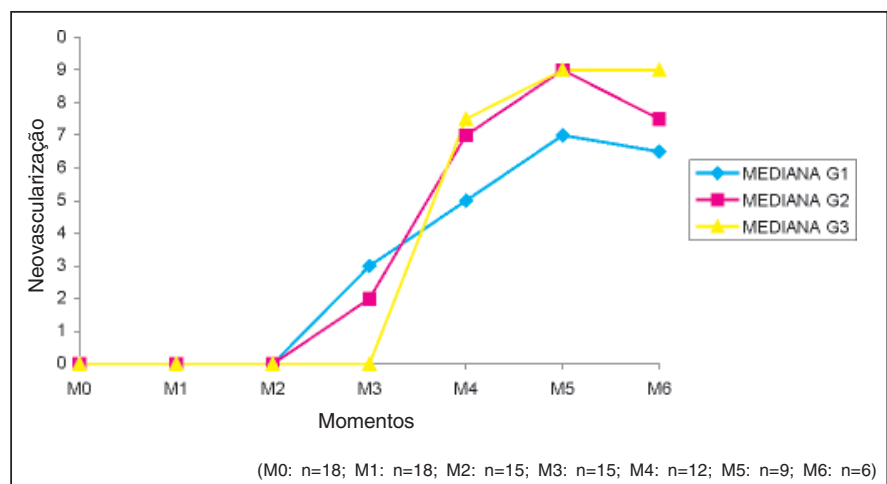

Gráfico 1 - Representação gráfica comparativa dos valores da mediana da neovascularização corneana global em função dos momentos, nos três grupos experimentais 


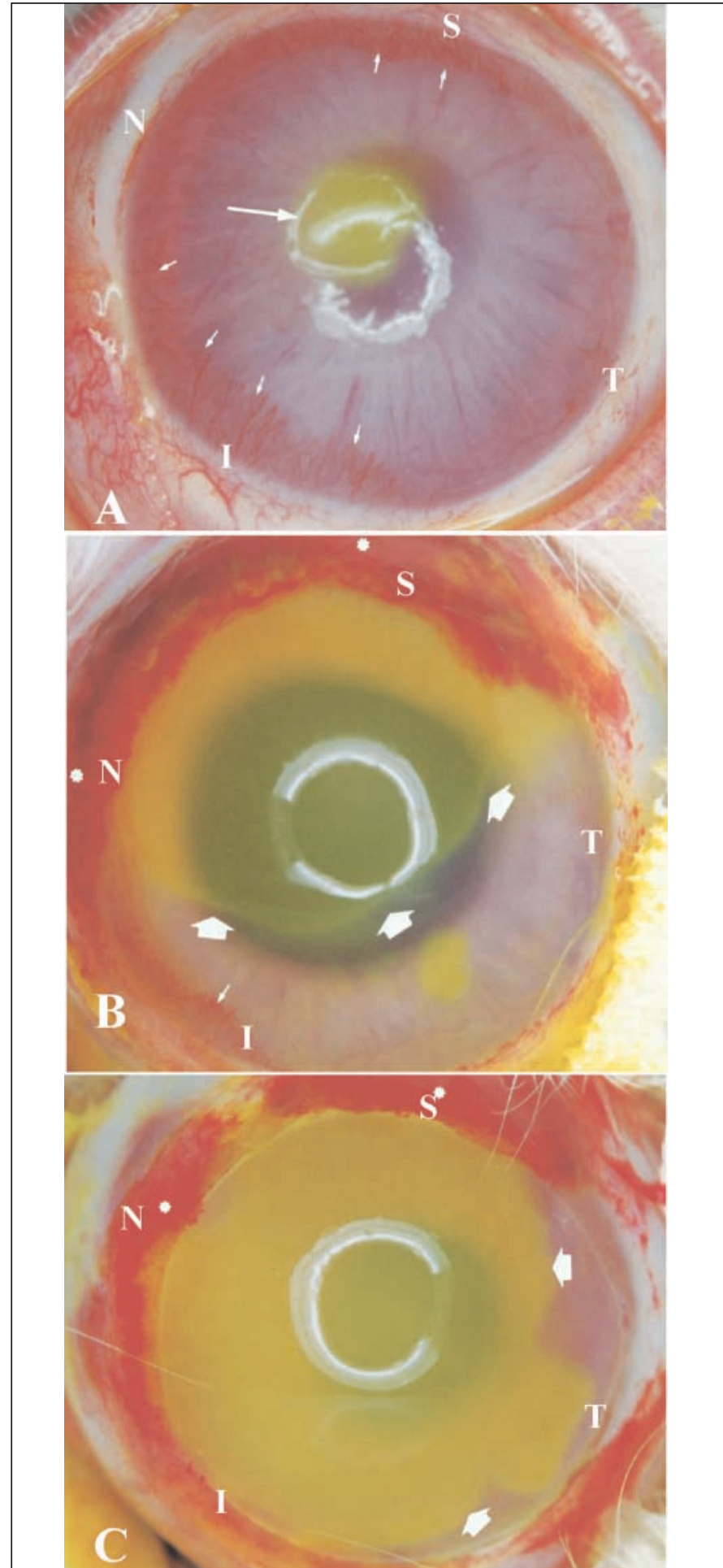

Figure 2 - Fotografias dos olhos em M3 ( $7^{\circ}$ dia). As córneas estão coradas com fluoresceína. Observam-se o surgimento de neovascularização corneana periférica, principalmente em A (G1), também em B (G2) (setas pequenas) e ausente em C (G3); a reparação epitelial corneana, mais avançada em A, restando $6,07 \%$ da superfície corneana a ser reepitelizada (seta comprida), intermediária em B, assimétrica e resta $61,05 \%$ da superfície corneana a ser reepitelizada (setas largas) e mais lenta em C (setas largas), resta $82,05 \%$ da superfície corneana a ser reepitelizada; e a perda da transparência corneana, menor em $A, 1(+)$, intermediária em $\mathrm{B}, 3(+)$ e maior em C, 4(+). Os asteriscos pequenos mostram em B e C sangue oriundo do rompimento dos frágeis neovasos límbicos. (quadrante superior $(\mathrm{S})$, inferior $(\mathrm{I})$, nasal $(\mathrm{N})$, temporal $(\mathrm{T})$ ) resultados homogêneos de neovascularização corneana global máxima.

A progressão da neovascularização corneana nos quadrantes ocorreu de forma assimétrica, a partir de M4. Houve um crescimento mais rápido dos vasos dos quadrantes superior e inferior, que passaram a ocupar a maior parte da superfície corneana e pareceram inibir o crescimento dos vasos dos quadrantes nasal e temporal. Essa diferença de neovascularização entre os quadrantes, maior nos quadrantes superior e inferior e menor nos quadrante nasal e temporal, foi estatisticamente significativa nos momentos utilizados para avaliação (M4 e M6). Interessante ressaltar também que, em M4, houve tendência de neovascularização maior na T2 e T3 do que na $\mathrm{T} 1$, nos quadrantes superior e temporal.

\section{Perda da transparência}

Após a realização das técnicas experimentais, percebeu-se uma progressiva opacificação da córnea até M2 ( $\left.3^{\circ} \mathrm{PO}\right)$, nos três grupos experimentais, de forma semelhante. Em M3, houve aumento da opacificação corneana para T2 e T3, enquanto para a T1 houve diminuição. Nos momentos seguintes, a perda da transparência corneana tendeu a manter-se estável nos três grupos experimentais (Gráfico 2, Figura 3). No entanto, a prova de Friedman mostrou não haver diferença significava na progressão da perda da transparência corneana, ao se compararem os momentos dentro de cada grupo. A prova de KruskalWallis mostrou que a perda da transparência similar entre a T2 e T3, ambas maiores que a T1, foi estatisticamente significativa nos momentos M3, M4, M5 e houve tendência à significância em M6.

\section{Irregularidade da superfície}

Cabe lembrar que, como em M1 e M2 não havia córneas dos três grupos experimentais epitelizadas, esse parâmetro não foi avaliado. Em M3 e M4, parte das córneas não estava epitelizada, de forma que isso impossibilitou qualquer análise. Somente em M5, quando todas córneas dos três grupos epitelizaram, e em M6, a irregularidade da superfície pôde ser estatisticamente comparada entre os grupos (Gráfico 3).

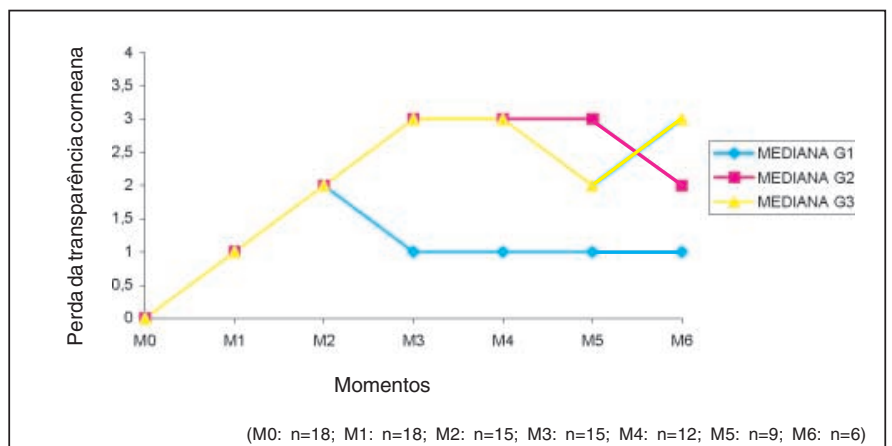

Gráfico 2 - Representação gráfica comparativa dos valores da mediana da perda da transparência corneana em função dos momentos, nos três grupos experimentais 


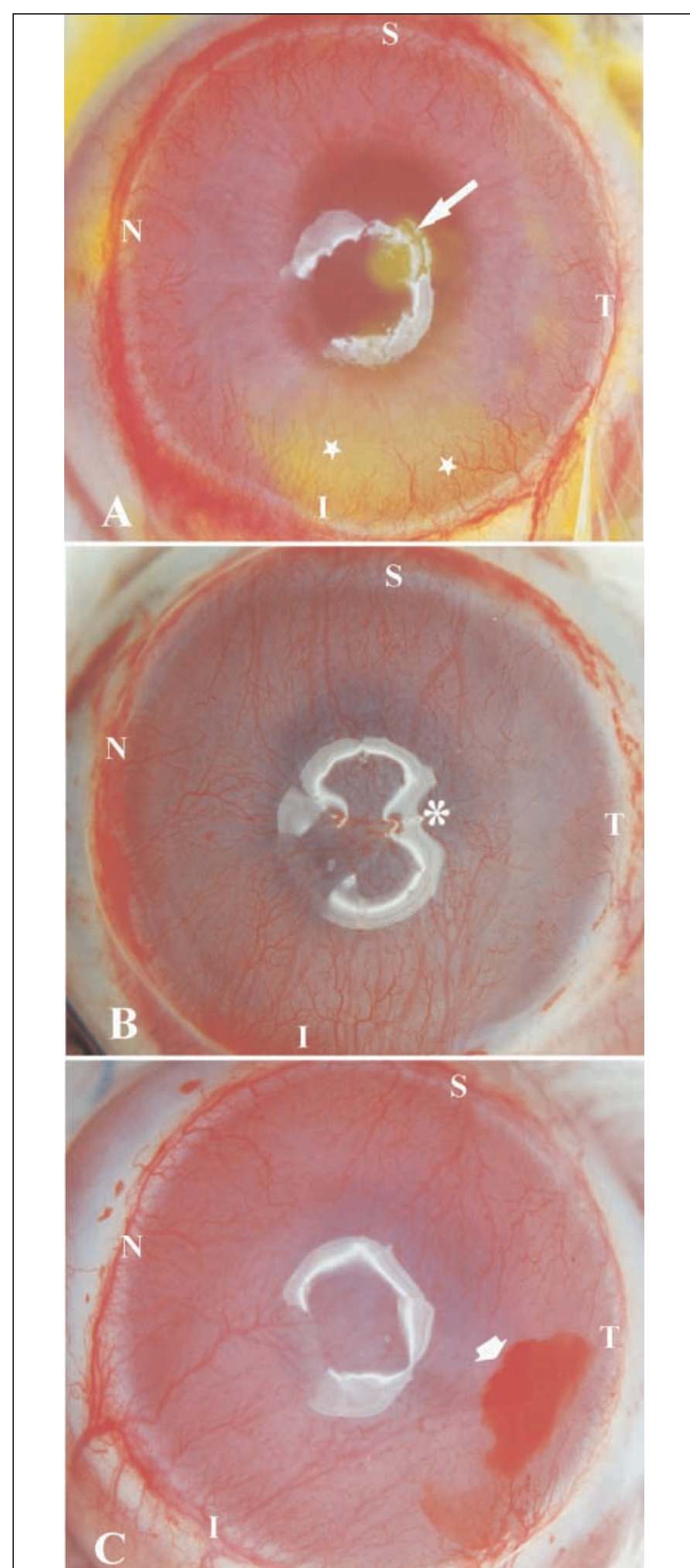

Figura 3 - Fotografias dos olhos em M6 (56 dia). Observam-se a neovascularização e a perda da transparência corneana, maiores em $B$ (G2) e C (G3) e menores em A (G1). A superfície corneana está corada com fluoresceína apenas em $A$, onde percebem-se erosão epitelial central (seta grande) e lesões puntatas confluentes (estrelas pequenas). Em B, percebem-se perda da transparência corneana e neovascularização corneana máximas (asterisco grande). Em C, observe-se, a similaridade com B. Percebe-se um neovaso corneano sangrante no quadrante temporal (seta larga)
A irregularidade da superfície foi observada na totalidade das córneas operadas e manteve-se constante em ambos os momentos (M5 até M6). A superfície corneana mostrou tendência a ser mais irregular na T2 e T3 do que na T1.

\section{Reparação epitelial}

O início da reparação da superfície epitelial corneana nos três grupos experimentais ocorreu a partir do M2.

As curvas de reparação da superfície epitelial corneana mostram retardo significativo na reparação da superfície corneana na $\mathrm{T} 2$ e $\mathrm{T} 3$ em relação à T1 (Figura 2, Gráfico 4). O retardo para a reparação foi similar na T2 e T3.

\section{Erosão epitelial, granuloma e outras lesões corneanas}

A presença de erosão epitelial inequívoca foi observada em 2 córneas do G1, em M6; em 2 córneas do G2, 1 em M5 e outra em M6, e em 2 córneas do G3, em M6. Foi observado granuloma em uma córnea do G1, em M6, em 2 córneas do G2, uma em M5 e a outra em M6 e em uma córnea do G3, em M6. Observou-se uma úlcera, provavelmente infecciosa, na córnea 9 do G3, no M4. O coelho foi excluído. Observou-se uma macrobolha sub-epitelial na córnea 10 do G3, no M4.

\section{DISCUSSÃO}

Um modelo de destruição das CG deve proporcionar obtenção de conjuntivalização (recobrimento da córnea por epitélio de fenótipo conjuntival) e neovascularização (crescimento de tecido fibrovascular abaixo do epitélio) em alto percentual de córneas operadas, deve ser reprodutível e, de preferência, ter fácil execução. As alterações provocadas devem ser superficiais na córnea, de forma a permitir a correlação com as alterações provocadas pelas doenças da superfície ocular. O modelo deve estimular a neovascularização, a perda da transparência corneana, a conjuntivalização e outras alterações similares às vistas nessas doenças. No entanto, deve-se considerar a existência de dificuldades ao se compararem modelos

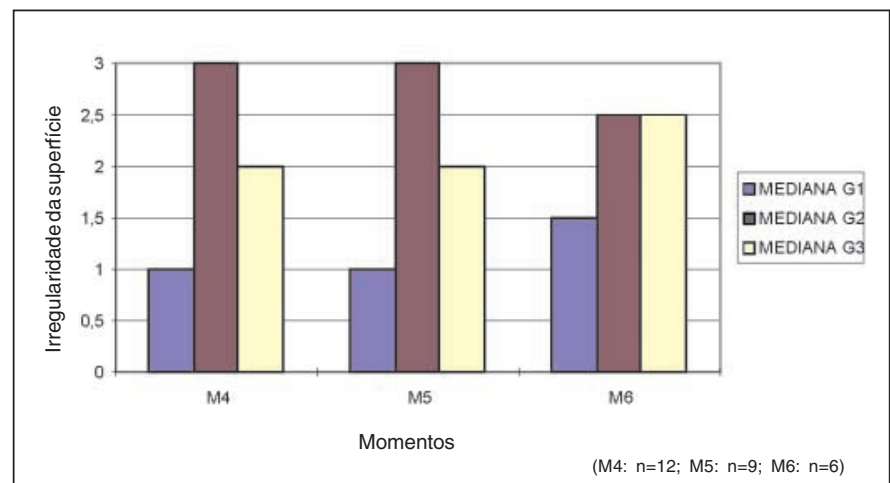

Gráfico 3 - Representação gráfica comparativa dos valores da mediana da irregularidade da superfície corneana em função dos momentos, nos três grupos experimentais 


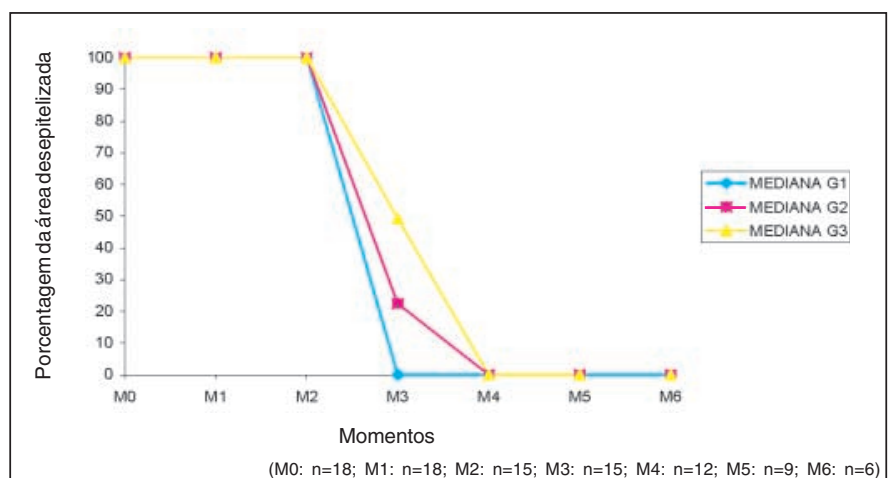

Gráfico 4 - Representação gráfica comparativa dos valores da mediana da porcentagem da área desepitelizada da superfície corneana em função dos momentos, nos três grupos experimentais

em animais com doenças humanas, devido às diferenças anatômicas e histológicas inerentes a cada espécie.

Para remoção do epitélio corneano, já foram utilizados vários métodos: escarificação mecânica, álcool etílico, n-heptanol e outros $^{(9)}$. O n-heptanol é capaz de remover o epitélio corneano sem lesar sua membrana basal ${ }^{(4)}$. Esta técnica também foi utilizada aplicando o n-heptanol até 2 a $3 \mathrm{~mm}$ da conjuntiva perilímbica ${ }^{(5)}$. Posteriormente outros autores, ao estudarem as células caliciformes e a vascularização durante o processo de transdiferenciação conjuntival (processo de transformação, atualmente considerado superado, pelo qual passariam as células conjuntivais, que migraram sobre a córnea em casos de reparação epitelial com disfunção das CG, ao assumir o fenótipo corneano ${ }^{(3,7,10)}$, incluíram também a escarificação mecânica perilímbica ${ }^{(5)}$. Utilizando esta técnica, autores mencionaram a ocorrência de vascularização em parte das córneas e não vascularização na outra parte, de forma imprevisível ${ }^{(6)}$. A partir deste último trabalho ${ }^{(6)}$, os que se seguiram, visando estudar a suposta transdiferenciação conjuntival, incluíram a escarificação mecânica da conjuntiva perilímbica para remoção das $\mathrm{CG}^{(11-14)}$. Posteriormente ainda, outros utilizaram para remoção das CG, debridamento por iodo, aplicação de n-heptanol ou escarificação, ao qual associaram incisões penetrantes lineares ou trepanações ${ }^{(15)}$.

Com uso do n-heptanol com ou sem escarificação mecânica, foi mencionada incidência, não previsível, de córneas vascularizadas $^{(7)}$. Trabalhos prévios ${ }^{(5-6,11-13,16)}$ mostraram incidência de 14 a $68 \%$ de córneas vascularizadas e o restante de córneas não vascularizadas com suposta transdiferenciação conjuntival. Sugeriram acrescentar um novo passo às técnicas de ablação do limbo que visassem à vascularização corneana, a remoção de todo tecido epitelial límbico por meio da dissecção lamelar da região e obtiveram $96 \%$ de córneas vascularizadas. A dissecção lamelar foi utilizada em diferentes experimentos, em que se buscava avaliar a reserva proliferativa das CG, frente a diferentes proporções de lesão ao limbo ${ }^{(17-19)}$ e para obtenção de córneas vascularizadas ${ }^{(8,20-23)}$.

No presente trabalho, as técnicas experimentais foram idealizadas buscando-se obter a remoção completa das CG, variando-se a profundidade da remoção da região límbica. A técnica 1 (T1) consistiria na remoção dos epitélios corneano e límbico e foi idealizada baseando-se em trabalhos precedentes ${ }^{(4-5)}$. A técnica 2 (T2) consistiria da remoção dos epitélios corneano e límbico e do tecido límbico sub-epitelial e foi idealizada baseando-se em outro ${ }^{(6)}$. A técnica 3 (T3) consistiria da remoção do epitélio corneano e dissecção lamelar do limbo e foi idealizada baseando-se também em outros trabalhos ${ }^{(7-8)}$. Utilizou-se, nas três técnicas experimentais, o n-heptanol, por 5 minutos, que por si só seria suficiente para remover a totalidade do epitélio límbico ${ }^{(7)}$.

As três técnicas experimentais produziram algum grau de neovascularização em $100 \%$ dos casos. O surgimento foi mais precoce na T1 e T2. Percebeu-se que, embora o surgimento de neovasos tenha ocorrido mais tardiamente no T3, a progressão da neovascularização foi mais rápida e logo se tornou mais acentuada do que na T1 e T2. Ao final do experimento, a neovascularização, nos três grupos variou de leve a intensa. É preciso lembrar que nenhuma das três técnicas produziu resultados homogêneos de neovascularização corneana global máxima. Embora não tenha havido diferença significativa entre os grupos na obtenção de córneas vascularizadas, no geral, a T1 proporcionou uma neovascularização menor quando comparada às outras técnicas. $\mathrm{O}$ padrão de neovascularização mencionado foi semelhante ao já referido na literatura ${ }^{(22-23)}$. A neovascularização corneana assimétrica também é referida por outros autores ${ }^{(2,15)}$. Por outro lado, mencionava-se vascularização concomitante e simétrica em todos os quatro quadrantes ${ }^{(22)}$.

A opacificação da córnea é de grande importância, pois está diretamente relacionada à diminuição da visão. A progressão da perda da transparência foi similar à comentada por outros autores ${ }^{(22)}$. Foi possível perceber uma correlação proporcional entre perda da transparência corneana e a neovascularização, ou seja, notou-se que uma córnea acentuadamente vascularizada também apresentou um máximo de opacificação, o que também já foi observado ${ }^{(8)}$.

O início da reparação da superfície epitelial corneana nos três grupos experimentais ocorreu a partir do M2. Essa demora no início da reparação nos grupos experimentais corresponde a uma fase latente aumentada e se deve, talvez, ao tempo necessário para que antes ocorra o reparo da região límbica. Utilizando a microscopia confocal, foi possível perceber claramente as bordas do epitélio regenerativo em casos de deficiência límbica, somente a partir de uma semana ${ }^{(23)}$. O maior retardo da reparação da superfície epitelial corneana na T2 e $\mathrm{T} 3$ em relação à $\mathrm{T} 1$ correlacionou-se bem com a maior destruição do epitélio límbico nesses dois grupos. No entanto, a avaliação deste parâmetro ficou prejudicada em virtude do espaçamento de dias entre os momentos, quando as córneas submetidas às técnicas experimentais não foram examinadas. Para uma melhor avaliação desse parâmetro, seria necessário, no mínimo, uma avaliação diária.

Na maior parte das córneas submetidas às técnicas experimentais, a epitelização se iniciou pela periferia próxima ao 
limbo de alguns quadrantes e houve tendência a progredir circunferencialmente e, ao mesmo tempo, de forma centrípeta, em direção ao centro. Em geral, a última área a epitelizar foi a periferia de algum quadrante, mais comumente o superior, tendo sido completada com a união das margens de crescimento circunferencial e centrípeto. Esse padrão de epitelização foi muito semelhante ao descrito no homem ${ }^{(24)}$. No entanto, observaram-se vários casos de padrão de epitelização apenas centrípeta, na qual a região central foi a última a epitelizar. A forma da área desepitelizada foi muito irregular, não podendo ser estabelecido um formato predominante.

A maioria dos autores é unânime em apontar a alta freqüência de erosões epiteliais em disfunção das $\mathrm{CG}^{(1,7-8,20,23,25)}$. Eles indicam que o dano à superfície ocular envolvendo $\mathrm{CG}$ pode afetar seriamente a reparação do epitélio, resultando em epitelização deficiente, caracterizada por erosões recorrentes e defeitos epiteliais persistentes. A presença de erosões epiteliais foi observada em $45 \%$ das córneas operadas com técnica similar a T3 ${ }^{(25)}$. Ao discutir, a reparação da superfície epitelial na deficiência parcial de limbo, alguns trabalhos ressaltando a dor e o desconforto oculares ocasionados pelas alterações epiteliais, além da conseqüente diminuição da visão devida à irregularidade da superfície óptica ${ }^{(2)}$.

Os granulomas corneanos são alterações vistas tardiamente no processo de neovascularização corneana. Nesse trabalho foram observados em aproximadamente $8 \%$ das córneas. Trabalho precedente mencionou alta freqüência de aparecimento de granulomas em disfunção das CG, mas não se referiram aos números ${ }^{(1)}$

Contrariando, em parte, o que foi observado ${ }^{(7)}$, obtivemos um padrão de regularidade na obtenção de córneas neovascularizadas e conjuntivalizadas não só com a dissecção lamelar do limbo (T3), mas também com a peritomia e escarificação do limbo (T2). A similaridade dos resultados obtidos com as duas técnicas (T2 e T3) pode ser explicada pelo fato de a escarificação do limbo proporcionar também remoção substancial do epitélio límbico e de suas CG.

Os modelos correspondentes a T2 e T3 podem ser utilizados quando se deseja causar ampla destruição das CG. Como vimos, tais modelos produziram alterações bastante similares nos diversos parâmetros estudados. É preciso lembrar que a T2 é de execução mais rápida, além de tecnicamente ser de mais fácil realização, sendo esta uma razão que justificaria a sua utilização no lugar da T3. Por outro lado, devemos considerar que, nos últimos trabalhos publicados na literatura mun$\operatorname{dial}^{(7,8,20,22-23)}$, nos quais se precisou obter córneas vascularizadas, foi utilizada a dissecção lamelar do limbo para remoção completa das CG.

A $\mathrm{T} 1$, podemos concluir, é inadequada como modelo de destruição total das CG por diversos motivos já apresentados anteriormente, mas, principalmente, pela remoção apenas parcial do epitélio límbico e uma neovascularização corneana mais débil. No entanto, esse modelo pode ser útil quando se deseja causar apenas a remoção parcial do epitélio límbico de forma a simular uma disfunção límbica.

\section{ABSTRACT}

Purpose: To compare the clinical aspects of three experimental models of limbal stem cell (SC) deficiency in rabbits. Methods: In the present study, 54 rabbits (108 eyes) were divided into 3 experimental groups - (G1), (G2) and (G3). Each group consisted of 18 rabbits. The left eyes were submitted to 3 different experimental techniques - (T1), (T2) and (T3), respectively. A control group was formed with the 54 remaining eyes (RE). In all 3 techniques n-heptanol was used. In T1, the epithelium was removed by applying n-heptanol for 5 minutes. In T2, the n-heptanol application was followed by a $360^{\circ}$ conjunctival peritomy at $4 \mathrm{~mm}$ beyond the limbus and scraping of the episcleral tissue. In $\mathrm{T} 3$, besides the procedure followed in T2, a lamellar dissection towards the limbus was performed, including $1.5 \mathrm{~mm}$ of the peripheral cornea and $2 \mathrm{~mm}$ of the scleral surface. Six clinical parameters of the corneas were studied: neovascularization, opacity, surface irregularity, epithelial wound healing, epithelial erosion, presence of granuloma and other injuries. Results: Corneal neovascularization started earlier in G1 and G2. It occurred heterogeneously, ranging from mild to intense, in $100 \%$ of the cases. It remained stable from the 28 th day up to the end of the experiment (56th day). It was more intense in the upper and lower corneal quadrants and less intense in the nasal and temporal quadrants. Corneal opacity and irregularity of the corneal surface were less intense in G1 than in G2 and G3, which were similar. Reepithelialization started after a 3-day latency period in all the animals submitted to the three experimental techniques and was complete on day 7 in G1 and day 14 in G2 and G3. The rate of occurrence of corneal epithelial erosion and corneal stromal granuloma were similar in the 3 groups. Conclusions: T2 and T3 seemed to be suitable experimental models for total limbal stem cell deficiency and most of the parameters showed similar results. T1 was found to be an appropriate model for the partial-thickness removal of limbal SC. Conjunctivalization and neovascularization occurred in all experimental models.

Keywords: Germ cells; Limbus corneal; Models, animal; Rabbits

\section{REFERÊNCIAS}

1. Tseng SC, Chen JJ, Huang AJ, Kruse FE, Maskin SL, Tsai RJ. Classification of conjunctival surgeries for corneal diseases based on stem cell concept. Ophthalmol Clin North Am 1990;3:595-611.

2. Chen JJ, Tseng SC. Abnormal corneal epithelial wound healing in partialthickness removal of limbal epithelium. Invest Ophthalmol Vis Sci 1991;32:2219-33.

3. Dua HS. Stem cells of the ocular surface: scientific principles and clinical applications. Br J Ophthalmol 1995;79:968-9. 
4. Cintron C, Hassinger L, Kublin CL, Friend J. A simple method for the removal of rabbit corneal epithelium utilizing $\mathrm{n}$-Heptanol. Ophthalmic Res 1979;11:90-6.

5. Shapiro MS, Friend J, Thoft RA. Corneal re-epithelialization from the conjunctiva. Invest Ophthalmol Vis Sci 1981;21:135-42.

6. Tseng SC, Hirst LW, Farazdaghi M, Green WR. Goblet cell density and vascularization during conjunctival transdifferentiation. Invest Ophthalmol Vis Sci 1984;25:1168-76.

7. Kruse FE, Chen JJ, Tsai RJ, TsEng SC. Conjunctival transdifferenctiation is due to the incomplete removal of limbal basal epithelium. Invest Opthalmol Vis Sci 1990;31:1903-13.

8. Tsai RJ, Sun TT, Tseng SC. Comparison of limbal and conjunctival autograft transplantation in corneal surface reconstruction in rabbits. Ophthalmology 1990;97:446-55.

9. Hirst LW, Kenyon KR, Fogle JA, Hanninen L, Star WJ. Comparative studies of corneal surface injury in the monkey and rabbit. Arch Ophthalmol 1981;99:1066-73.

10. Dua HS. The conjunctiva in corneal epithelial wound healing. Br J Ophthalmol 1998;82:1407-11.

11. Tseng SC, Farazdaghi M, Rider AA. Conjunctival transdifferentiation induced by systemic vitamin A deficiency in vascularized rabbit corneas. Invest Ophthalmol Vis Sci 1987;28:1497-504.

12. Tseng SC, Hirst LW, Farazdaghi M, Green WR. Inhibition of conjuntival transdifferentiation by topical retinoids. Invest Ophthalmol Vis Sci 1987;28:538-42.

13. Huang AJ, Watson BD, Hernandez E, Tseng SC. Induction of conjunctival transdifferentiation on vascularized corneas by photothrombotic occlusion of corneal neovascularization. Ophthalmology 1988;95:228-35.
14. Huang AJ, Tseng SC, Kenyon KR. Alteration of epithelial paracellular permeability during corneal epithelial wound healing. Invest Ophalmol Vis Sci 1990;31:429-35.

15. Thoft RA, Friend J, Murphy HS. Ocular surface epithelium and corneal vascularization in rabbits. I the role of wounding. Invest Ophthalmol Vis Sci 1979; 18:85-92.

16. Kinoshita S, Friend J, Thoft RA. Biphasic cell proliferation in transdifferentiation of conjunctival to corneal epithelium in rabbits. Invest Ophthalmol Vis Sci 1983:24:1008-14.

17. Chen JJ, Tseng SC. Corneal epithelial wound healing in partial limbal deficiency. Invest Ophthalmol Vis Sci 1990;31:1301-14.

18. Marinho DR, Lima ALH, Kwitko S, Kirst M, Mársico J, Roehe D. Corneal epithelial healing in rabbit eyes with partial corneal-conjunctival and conjunctival limbal deficiency. Arq Bras Oftalmol 1998;61:525-38.

19. Huang AJ, Tseng SC. Corneal epithelial wound healing in the absence of limbal epithelium. Invest Ophthalmol Vis Sci 1991;32:96-105.

20. Tsai RJ, Tseng SC. Effect of estromal inflammation on the outcome of limbal transplantation for corneal surface reconstruction. Cornea 199514:439-49.

21. Kim JC, Tseng SC. Transplantation of preserved human amniotic membrane for surface reconstruction in severely damaged rabbit corneas. Cornea. 1995; $14: 473-84$

22. Swift GJ, Aggarwal RK, Davis GJ, Coster DJ, Willians KA. Survival of rabbit limbal stem cell allografts. Transplantation 1996;62:568-74.

23. Cho BJ, Djalilian AR, Holland EJ. Tandem scanning confocal microscopic analysis of differences between epithelial healing in limbal stem cell deficiency and normal corneal reepithelialization in rabbits. Cornea 1998;17:68-73.

24. Dua HS, Forrester JV. The corneoscleral limbus in human corneal epithelial wound healing. Am J Ophthalmol 1990;110:646-56.

25. Huang AJ, Tseng SC. Corneal epithelial wound healing in the absence of limbal epithelium. Invest Ophthalmol Vis Sci 1991;32:96-105.

\title{
IX SIMPÓSIO INTERNACIONAL DE ATUALIZAC̣ÃO EM OFtaLmOLOGIA da santa casa de são paulo
}

\author{
04 A 06 DE JULHO DE 2002
}

Frei Caneca Shopping \& Convention Center

SÃO PAULO - SP

Informações: JDE Comunicações e Eventos

Tel.: (1 1) 287-8109 / 287-9378 • Fax: (1 1) 288-8157

e-mail: jdecomev@uol.com.br 